\title{
Systematic Review and Meta-analysis of Randomized Controlled Trials of Ayurvedic and Herbal dentifrices for Plaque reduction in Gingivitis
}

Danish Javed ( $\square$ danish.ayush@aiimsbhopal.edu.in )

All India Institute of Medical Sciences, Bhopal, M.P.

Ashish Kumar Dixit

All India Institute of Medical Sciences, Bhopal, M.P.

Sana Anwar

RKDF Dental College \& research center, Bhopal

Anshul Rai

All India Institute of Medical Sciences, Bhopal, M.P.

\section{Systematic Review}

Keywords: Gingivitis, Dental Plaque, Ayurvedic Medicine, Herbal Medicine, Plant Oils, Mouthwashes, Dentifrices

Posted Date: March 1st, 2022

DOI: https://doi.org/10.21203/rs.3.rs-1405356/v1

License: (9) (1) This work is licensed under a Creative Commons Attribution 4.0 International License. Read Full License 


\section{Abstract \\ Background}

Despite the existence of a large number of trials employing ayurvedic and herbal dentifrices to reduce plaque in gingivitis, the findings are inconsistent. Therefore, we assess the overall effect of ayurvedic and herbal dentifrices in gingivitis on dental plaque index (PI), gingival index and bacterial colony counts (CC) of debris.

\section{Methods}

We found 554 articles after searching PubMed, CAM-QUEST ${ }^{\circledR}$, and the Cochrane Central Register of Controlled Trials. 41 randomised clinical trials were considered for meta-analysis. The Standard Mean Difference (SMD) for effect size estimation with $95 \%$ confidence intervals $(\mathrm{Cl})$ was estimated using RevMan 5.4.1 software.

\section{Results}

A total 2,806 patients in 41 RCTs were participated. Ayurvedic dentifrices,Plaque index (PI): SMD $=-0.52$, 95\% Cl (-0.94,-0.11); CC: SMD $=-1.70,95 \% \mathrm{Cl}(-5.06,1.67)$, (Oil pulling therapy :PI: $S M D=-0.38,95 \% \mathrm{Cl}$ $(-1.45,0.68)$; CC: SMD $=-1.04,95 \% \mathrm{Cl}(-2.20,0.11)$, Herbal Dentifrices :PI: SMD $=-0.58,95 \% \mathrm{Cl}(-1.55,0.39)$, (Triphala :PI: SMD $=-0.65,95 \% \mathrm{Cl}(-1.32,0.03)$ were found as good as control.

\section{Conclusions}

In addition to conventional dental care, ayurvedic and herbal dentifrices may help in plaque reduction, gingival inflammation, and bacterial growth. They are safe and may be recommended in community dentistry practices.

\section{Introduction}

Gingivitis is one of the most common oral health problems, and it can lead to more serious issues with teeth and other oral cavity structures. ${ }^{[1]}$ Plaque is caused by poor dental hygiene in the majority of the population. ${ }^{[2]}$ Plaque control is strongly suggested, and it has also been established as a method of treating gingivitis. ${ }^{[3]}$ The accumulation of microbial plaque causes calculus to form on tooth spaces, increasing the risk of periodontitis, which can lead to tooth loss, dental cavities, foul breath, and a poor quality of life. ${ }^{[4]}$ 
Self-performed mechanical and chemical oral hygiene measures include tooth brushing, dental flossing, dentifrices, and mouth rinse. ${ }^{[5]}$ For plaque control, traditional dentifrices and mouth rinse are regarded gold standard antimicrobial agents. The most often used chemical agent is Chlorhexidine (CHX), but its deleterious effects on the oral mucosa, staining properties, and taste sense alterations discourage its usage and reduce acceptance. ${ }^{[6]}$

Herbal, biogenic, botanical, plant-based, or ayurvedic dental preparations are now thriving in the global market to replace conventional dentifrices, with manufacturers claiming them to be safe and effective oral health preventers in terms of plaque control, tooth decay prevention, gingival inflammation prevention, and fresh breath. ${ }^{[7]}$ Ayurveda pharmaceutical goods are presently in significant demand on the global market, especially in India. ${ }^{[8]}$ The vast spectrum of qualities such as anti-inflammatory, antimicrobial, anti-oxidant, and anti-cancerous, as well as good natural flavour and feel, have led to widespread adoption of these products among the general public. General practitioners in India employ a variety of ayurvedic remedies to treat oral diseases. ${ }^{\left[{ }^{[9]}\right.}$ The majority of these preparations come in the form of herbal powder, which should be rubbed on teeth after being wetted with water with a finger or brush. Brushing with twigs from a variety of plants is recommended daily. Oil pulling therapy is also recommended for better oral health and cleanliness, in which therapeutic oil is rubbed inside the buccal cavity. These plant-based extracts and essential oils are being used in herbal toothpastes. ${ }^{[10]}$

Although a considerable number of randomised clinical trials involving herbal and ayurvedic medicines as well as oil pulling therapy in patients with plaque-induced gingivitis have been conducted, the results are contradictory and unconvincing. ${ }^{[11]}$ Herbal dentifrices are as effective as conventional in preventing plaque growth, according to a few systematic literature reviews and meta-analyses. ${ }^{[12-14]}$ Although data from randomised clinical trials on ayurvedic and herbal products and therapy were used, thorough evidence-based research was needed to provide patients with the best possible care. Therefore, this study aimed to conduct a systematic review and meta-analysis of randomised controlled trials (RCTs) to compare the overall effect of herbal and ayurvedic preparations as a complement to regular oral hygiene for plaque control and gingival inflammation to placebo and control in the treatment of gingivitis.

\section{Material And Methods}

\subsection{Objectives:}

1. To find the overall effect of ayurvedic and herbal dentifrices i.e. toothpaste, toothpowder, gel, mouth rinse in patients of gingivitis on dental plaque index, gingival index and bacterial colony counts of debris present over plaque or in saliva.

2. To find the effective plant species used in herbal dentifrices against plaque control.

\subsection{Methods:}


Preferred Reporting Items for Systematic Review and Meta-analysis (PRISMA) guidelines were followed for reporting this systematic review. ${ }^{[15]} A$ detailed protocol was prepared initially and registered in the International Prospective Register of Systematic Review (http://www.crd.york.ac.uk/PROSPERO/) and obtained the registration no:)

\section{Criteria for Considering Studies for this Systematic Review and Meta-analysis:}

2.2.1 Participants-Interventions-Comparators-Outcomes-Study design (PICOS) Questions. This systematic review was executed mainly focused on the question i.e. "How are the ayurvedic and herbal dentifrices efficacious in plaque control in teeth and to reduce gingival inflammation and bacterial load in tooth debris?"

Types of studies: Only randomized clinical trials (RCTs) related to the above question were included in this study.

Types of participants: Patients diagnosed as established gingivitis and otherwise having no other dental or systemic disease.

Types of interventions: Any intervention in form of herbal or ayurvedic toothpaste, toothpowder, gel, mouth rinse in form with or without mechanical use of the toothbrush, floss etc. Herbal dentifrice should consist of at least one of its components as the herb. Multiple combinations of plant products were called Herbal and classical or patent ayurvedic formulations were called ayurvedic. Oil pulling therapy i.e. rinsing the mouth with any type of single or poly herbal-based oil or essential oil was considered under Oil pulling therapy.

Type of comparison: Any comparator either a negative placebo, control having chlorhexidine or any other antiseptic compound, and conventional toothpaste or mouth rinse not containing any herbal or botanical component as a constituent was considered.

Types of outcome measures: The clinical effect of intervention or control that was established on the certain parameters of plaque index, gingival index and colony count.

\section{Primary outcomes:}

1. Plaque index: Standard mean difference (SMD) of QHPI (Quigley and Hein plaque index), TQHPI (Turesky-Gilmore-Glickman modification of Quigley-Hein plaque index) or SLPI (Silness and Löe Index).

2. Gingival index: Standard mean difference (SMD) of LSGI (Löe and Silness Gingival Index).

3. Colony-forming unit (CFU) Standard mean difference (SMD) of Colony Counts.

Secondary outcomes: Adverse event if any, 
2.2.2 Eligibility criteria: Based on the PICOS question, the following inclusion criteria were made to fulfill compulsorily by all the included studies:

1. All the participants must be diagnosed case of gingivitis and should not contain any other dental or systemic illness.

2. The dentifrice of intervention should be having at least one or more active herbal ingredients, natural or plant extract.

3. The dentifrice of the comparison group must be any product that does not have any herbal or plantbased component.

4. The above intervention or control should be used by subjects along with the self-performed mechanical oral hygiene measures i.e. toothbrush, finger or any other means.

5. The outcome of the study must include plaque index, gingival index or colony count as one of the assessment parameters.

6. Randomized clinical trials (RCTs) only will be included.

Exclusion criteria: All the studies, other than RCT i.e. quasi-randomized trial, clinical study, observational study, cohort study, Cross-sectional study, case report, in-vivo, in-vitro study, systematic reviews were excluded.

\subsubsection{Search methods for identification of studies}

An exhaustive literature search was conducted on online databases like PubMed/Medline, CAM-QUEST ${ }^{\circledR}$, and the Cochrane Central Register of Controlled Trials in August 2021. Unpublished studies were also looked for in the grey literature. The search was conducted using keywords such as gingivitis, dental plaque, dental plaque index, Ayurvedic, Herbal Medicine, Phytotherapy, Plant Preparations, Plant Oils, and Mouthwashes. Only publications written in English were considered, and there was no time limit on the studied period. For a more comprehensive search of articles, the Boolean operators 'AND' and 'OR' were used. Other relevant articles were found by looking through the references of the retrieved articles.

2.2.4 Selection of studies: Two authors (DJ and AKD) independently checked all of the articles for duplication. For inclusion and exclusion criteria, the title and abstract were carefully scrutinized. The articles' full text was examined and checked for eligibility criteria. If a full-text version of an article was not accessible, the relevant author was contacted to request it. Either the Researchgate website or e-mail was used to make the request. Any article that had a single exclusion term was not considered for further investigation. If there was a disagreement about whether a study should be included or excluded, it was addressed through discussion or by a third reviewer (SA).

2.2.5 Data collection process and data items: All the details of included RCTs were filled in preformed Microsoft Excel Sheet in participant study definition, risk of bias assessment, total length of study, unit of randomization, unit of analysis, participants characteristics, intervention, control, outcome, result and other items systematically by two reviewers. The treatment effect for each study was summarized using 
mean differences (MD) and standard deviations ( $\pm S D$ ). The standardized weighted-mean differences (SMD) were calculated for outcomes (measured by different scales or indices) for each study. Randomeffects models were used to calculate a pooled estimate of effect and its $95 \%$ confidence intervals (Cls).

[16] The corresponding author of the included article was contacted in the event of missing data. Nonreported SDs were calculated from the reported standard errors, confidence intervals, presented for mean differences. Data were analyzed with RevMan 5.4.1 software Cochrane Collaboration and forest plots were generated by using the same.

\subsubsection{Assessment of risk of bias in included studies:}

The risk of bias assessment of the included studies used the approach recommended by the Cochrane Collaboration's tool. ${ }^{[17]}$ Two review authors (DJ and AKD) independently and in duplicate analysed all included articles for study design characteristics and internal validity criteria. Within and among studies, assessments were carried out. The first step was to provide a summary of the findings from each of the studies that were included. We included publication details author, year of publication, and study period in the study characteristics. To assess the risk of bias in the included research, the methodological quality of each study was noted.

The risk of bias was then assessed, with each included study receiving a score of low, high, or unclear, as specified in the Cochrane Handbook for Systematic Reviews of Interventions. The tool developed by the Cochrane Collaboration was used to assess the risk of bias. For this objective, the following criteria were evaluated: 1. Randomization methods, 2. Allocation concealment, 3. Blinding of participants and personnel, 4. Blinding of outcome assessment, 5. Incomplete outcome data, 6.Selective reporting, and 7. Other bias.

Each study was assessed independently for the risk of bias. The author and source institution were not masked from the reviewers. Any disagreements were resolved through discussion or adjudication by a third party.

2.2.7 Missing data: Wherever possible, missing data were gathered from authors, and the causes for missing data (attrition rates, such as drop-outs, losses to follow-up, and withdrawals), as well as issues with missing data and imputation methods, were studied and critically evaluated. Missing standard deviations (SD) were imputed (average of SD of studies where reported), and sensitivity analyses were used to investigate the impact of imputation on meta-analyses.

2.2.8 Assessment of heterogeneity: Causes of any significant clinical, methodological, or statistical heterogeneity were explored but the pooled effect estimate in a meta-analysis was still presented. Heterogeneity was identified through visual inspection of the forest plots and by using a standard chisquare test $a$ and the $I^{2}$ statistic $<75 \%$.

If 5 or more studies were included investigating a particular outcome, funnel plots were used to assess small study effects. Several explanations can be offered for the asymmetry of a funnel plot, including 
true heterogeneity of effect for trial size, poor methodological design and hence bias.

\subsubsection{Synthesis of results:}

We used Cochran's Q statistic, a chi-square test, and a cutoff p-value of less than 0.05 to assess the data's heterogeneity. ${ }^{[18]}$ The $I^{2}$ statistic and forest plots were used to assess the consistency of the results. ${ }^{[19]}$ In comparison to sampling error, the $\mathrm{I}^{2}$ statistic describes the proportion of variation in point estimates related to heterogeneity. For the graphic presentation, forest plots were employed.

\section{Results}

\subsection{Search results:}

A total of 554 records were found after searching various databases, with 288 duplicates and 91 irrelevant records being removed. Following the screening of 175 citations, 91 articles were excluded due to non-English (16), non-availability of full-text articles (26), and after viewing the title and abstract of articles (49). Following that, 84 papers were reviewed for eligibility, with 43 being discarded for a variety of reasons; including the variation of RCT design (11) and follow-up (9), missing values (8), irrelevant indices (8), and other outcomes (7). In the end, this meta-analysis included 41 papers. Details are also shown in the PRISMA flowchart in Figure. 1.

\section{Figure 1: Study flow diagram}

3.2 Risk of bias within the study: The majority of studies have a low risk of bias, indicating that the analysis' results are trustworthy. Random sequence generation had a low risk of selection bias in $77.2 \%$ of trials, and allocation concealment had low risk in $65.8 \%$ of studies. In $65.8 \%$ of trials, blinding of participants and personnel (performance bias) was determined to be low risk. In $62 \%$ of trials, blinding of outcome assessment (detection bias) was a low risk. In the reviewed studies, incomplete outcome data (attrition bias) was $77.2 \%$, while selective reporting (reporting bias) was $82.2 \%$ low risk. In these studies, the risk of other bias was only $12.65 \%$. Figure: 2

Figure 2: Risk of Bias graph: review authors' judgments about each risk of bias item presented as percentages across all included studies.

\subsection{Characteristics of the included studies:}

We have included 41 randomized clinical trials in this meta-analysis in which data of a total of 2,806 patients were analyzed. Total drop-out patients were 43 among included studies. The characteristics of encompassed studies are highlighted in Table 1. All the studies were categorized by their main intervention as herbal, ayurvedic or single plant-based dentifrices viz. ayurvedic dentifrices ${ }^{[20-25]}(6)$, oil pulling therapy ${ }^{[26-31]}(6)$, herbal dentifrices ${ }^{[32-40]}(9)$, triphala ${ }^{[39,41-47]}(8)$, Aloe vera ${ }^{[48-50]}(3)$, Azadirachta indica $^{[51-53]}(3)$, Curcuma longa ${ }^{[54-56]}(3)$, green tea ${ }^{[57,58]}(2)$ and ocimum ${ }^{[59,60]}(2)$. Narayan, et al ${ }^{[39]}$ 
2012 has included 'Triphala and 'herbal' in both groups in the study, so this study was comprised in both the categories. Included studies were published from 2004 to 2020 in various indexed biomedical journals. These studies were open-labelled, single-blinded (6), double-blinded (32) or triple blinded (3), parallel (38) or cross over (3), randomized clinical trials. Included age groups were from 8 years to 70 years of age of both genders. Different studies included healthy people with mild or severe plaqueinduced gingivitis, DMFT (decayed/missing/filled teeth) scores of 2 to $6, \mathrm{Pl}>1$ or $\mathrm{Gl}>1$. Three groups were used in 16 studies: intervention, control, and placebo, with two studies involving four cross-over groups. The majority of the studies (21) were divided into 2 groups. In 30 studies, $0.1 \%$ chlorhexidine was used as a control. In 8 studies, standard or branded dentifrices were used as a control. In 10 trials, the placebo was saline or distilled water. In these studies, the duration of follow-up ranged from one hour to 90 days. In either of these investigations, no adverse events were observed as a result of the intervention.

\subsection{Meta-analysis comparing ayurvedic and herbal dentifrices with control:}

We observed significant differences in these analyses in favour of herbal and ayurvedic dentifrices as compare to control or placebo (Ayurvedic dentifrices to control: Plaque index: $S M D=-0.52,95 \% \mathrm{Cl}$ $(-0.94,-0.11) p=0.01$; heterogeneity $\mathrm{Chi}^{2}=6.73>3, \mathrm{I}^{2}=55 \%$; Colony Count: $\mathrm{SMD}=-1.70,95 \% \mathrm{Cl}(-5.06,1.67)$ $p=0.32$; heterogeneity $\mathrm{Chi}^{2}=78.96>1, l^{2}=99 \%$ ), (Oil pulling therapy: Plaque index: $\mathrm{SMD}=-0.38,95 \% \mathrm{Cl}$ $(-1.45,0.68) p=0.48$; heterogeneity $\mathrm{Chi}^{2}=26.67>3, R^{2}=89 \%$; Colony Count: $\mathrm{SMD}=-1.04,95 \% \mathrm{Cl}$ $(-2.20,0.11) p=0.08$; heterogeneity $\left.\mathrm{Chi}^{2}=7.82>2, \mathrm{l}^{2}=74 \%\right)$, (Herbal Dentifrices: Plaque index: $\mathrm{SMD}=-0.58$, $95 \% \mathrm{Cl}(-1.55,0.39) p=0.24$; heterogeneity $\left.\mathrm{Chi}^{2}=200.46>8, R^{2}=96 \%\right)$, (Triphala: Plaque index: $\mathrm{SMD}=-0.65$, $95 \% \mathrm{Cl}(-1.32,0.03) p=0.06$; heterogeneity $\left.\mathrm{Chi}^{2}=88.96>7, \mathrm{I}^{2}=92 \%\right),($ Aloe vera: Plaque index: $\mathrm{SMD}=-1.39$, $95 \% \mathrm{Cl}(-3.55,0.77) p=0.21$; heterogeneity $\left.\mathrm{Chi}^{2}=60.46>2, R^{2}=97 \%\right)$, (Azadirachta indica: Plaque index: $\mathrm{SMD}=-0.47,95 \% \mathrm{Cl}(-4.13,3.18) p=0.80$; heterogeneity $\mathrm{Chi}^{2}=72.25>2, R^{2}=97 \%$; Gingival index: $\mathrm{SMD}=$ $-0.91,95 \% \mathrm{Cl}(-2.38,0.56) p=0.23$; heterogeneity $\left.\mathrm{Chi}^{2}=6.69>1, R^{2}=85 \%\right)$, (Curcuma longa : Plaque index: $\mathrm{SMD}=-0.68,95 \% \mathrm{Cl}(-1.97,0.61) p=0.30$; heterogeneity $\mathrm{Chi}^{2}=33.94>2, R^{2}=94 \%$; Gingival index: $\mathrm{SMD}=$ $-0.97,95 \% \mathrm{Cl}(-1.88,-0.07) p=0.04$; heterogeneity $\left.\mathrm{Chi}^{2}=16.50>2, P^{2}=88 \%\right)$, (Green tea : Plaque index: $\mathrm{SMD}=0.16,95 \% \mathrm{Cl}(-2.31,2.64) p=0.90$; heterogeneity $\left.\mathrm{Chi}^{2}=29.10>1, R^{2}=97 \%\right)$, (Ocimum : Plaque index: $\mathrm{SMD}=-1.04,95 \% \mathrm{Cl}(-3.21,1.13) p=0.35$; heterogeneity $\left.\mathrm{Chi}^{2}=12.03>1,2=92 \%\right)$. Figure $\mathbf{3} \mathbf{a} \& \mathbf{b}$

Figure 3a: Forest plots of included studies

Figure 3b: Forest plots of included studies

3.5 Risk of bias across the studies: Meta-analysis included in ayurvedic, herbal dentifrices, oil pulling therapy and Triphala groups were having more than five studies. The funnel plot was intrigued through RevMan 5.4.1 software Cochrane Collaboration for them. However, the plots were found in favour of possible publication bias upon visual examination. Figure 4

Figure 4: Funnel plot of comparison: a. Ayurvedic preparation, b. Oil pulling therapy, c. Herbal Preparations and d. Triphala vs. Control, Outcome: Plaque Index. 


\section{Discussion}

In ancient Ayurveda text, dental diseases, their classification and symptoms, herbal formulations and dental procedures for oral health care have been described in details. As a result, numerous herbal and Ayurvedic pharmaceutical companies have begun to promote their dentifrices as safe and effective. The usefulness of several ayurvedic and herbal dental preparations has been summarized here. A major significance of ayurvedic medicines and oil pulling therapy was identified in this thorough meta-analysis research of 41 randomised clinical trials. These products have not been found to have any negative effects in any of the studies. The only issue with oil pulling therapy is that it is unpleasant to use. ${ }^{[29]}$ Some of the products in these RCTs contain a single herbal component, while others have a poly-herbal composition. However, formulations containing traditional Ayurveda combinations like Triphala, Dashan sanskarpowder, commercial patent ayurvedic formulations, and oil pulling therapy outperformed single or poly-herbal dentifrices in terms of plaque index, gingival index, and bacterial colony counts. However, the composition of these ayurvedic preparations is heterogeneous, with Acacia catechu, Acorus calamus, Aquilaria agallocha, Azadirachta indica, Barleria prionitis, Berberis aristata, Curcuma longa, Emblica officinalis, Glycyrrhiza glabra, Mimusops elengi, Mimosa pudica, Ocimum tenuiflorum, Prunus cerasoides, Santalum album, Syzygium aromaticum, Terminalia bellirica, Terminalia chebula, Woodfordia fruticosa, etc. ${ }^{[20-25]}$ In these studies, arimedadi oil, coconut oil, and sesame oil were used in oil pulling therapy, and their effi5cacy was determined to be as good as a positive control. ${ }^{[26-31]}$ We didn't separate the dentifrices in this meta-analysis, based on their medicinal type, such as toothpaste, toothpowder, mouth rinse, and so on. Our main focus was on their primary active plant material.

Though few meta-analyses on herbal dentifrices already reported its effectiveness but, this is the first meta-analysis of its kind on Ayurvedic dentifrices and oil pulling therapy that has been reported here. All of the studies in this review were MEDLINE-indexed, which means they can be found in large worldwide databases like PubMed and CAM-QUEST @. However, no subgroup analysis was performed, and only English language articles were included in this study. Another drawback was that many of the studies included were only undertaken for a short period, therefore there was no comparison to extended followup. No significant adverse event was documented in such large data and 41 RCTs, which is suspicious in and of itself.

Future RCTs in herbal dentistry should provide thorough uniform methods and outcomes reporting, adequate randomization, sufficient sample size, allocation concealment, and blinding of at least outcome assessors to improve high-quality evidence (e.g., CONSORT).

\section{Conclusion}

We may conclude from this comprehensive review that ayurvedic formulations as dentifrices are quite effective. However, to improve the documentation of findings, a little more rigorous and high-quality research work is suggested. 


\section{Appendix}

\section{Search protocol used electronic searches}

\section{(i) Pubmed:}

(("Gingivitis"[Mesh]) OR ("Dental Plaque"[Mesh] OR "Dental Plaque Index"[Mesh])) OR "Gingivitis, Necrotizing Ulcerative"[Mesh]

(((((("Medicine, Ayurvedic"[Mesh]) OR "Herbal Medicine"[Mesh]) OR "Phytotherapy"[Mesh]) OR "Plant Preparations"[Mesh]) OR "Plant Oils"[Mesh]))) AND "Mouthwashes"[Mesh] Sort by: Most Recent

((((((("Medicine, Ayurvedic"[Mesh]) OR "Herbal Medicine"[Mesh]) OR "Phytotherapy"[Mesh]) OR "Plant Preparations"[Mesh]) OR "Plant Oils"[Mesh]))) AND "Mouthwashes"[Mesh]) AND ((("Gingivitis"[Mesh]) OR ("Dental Plaque"[Mesh] OR "Dental Plaque Index"[Mesh])) OR "Gingivitis, Necrotizing Ulcerative"[Mesh])

RCTs- Timeline-1994-2021

RCTS- Timeline- 10 years.

\section{(ii) CAM-QUEST ${ }^{\circledR}$ :}

Search for diseases $>$ Dental Diseases $>$ Gingival Inflammation, Dental Plaque $>$ Ayurveda, Phytomedicine $>$ Randomized trial

\section{Declarations}

Acknowledgement: None.

Funding: None

Conflict of interest: None

\section{References}

1. Nazir MA. Prevalence of periodontal disease, its association with systemic diseases and prevention. Int J Health Sci. 2017;11:72-80.

2. Weijden GA, Hioe KPK. A systematic review of the effectiveness of self-performed mechanical plaque removal in adults with gingivitis using a manual toothbrush. J Clin Periodontol 2005;32:214-28.

3. Barnett ML. The rationale for the daily use of an antimicrobial mouthrinse. J Am Dent Assoc 2006;137:16-21.

4. Serrano J, Escribano M, Roldan S, Martín C, Herrera D. Efficacy of adjunctive anti-plaque chemical agents in managing gingivitis: a systematic review and meta-analysis. $\mathrm{J}$ Clin Periodontol 
2015;42:106-38.

5. Moran JM. Home-use oral hygiene products: mouthrinses. Periodontol 2008;48:42-53.

6. Teles RP, Teles FRF. Antimicrobial agents used in the control of periodontal biofilms: effective adjuncts to mechanical plaque control. Braz Oral Res 2009;23:39-48.

7. Howshigan J, Perera K, Samita S, Rajapakse PS. The effects of an Ayurvedic medicinal toothpaste on clinical, microbiological and oral hygiene parameters in patients with chronic gingivitis: a doubleblind, randomised, placebo-controlled, parallel allocation clinical trial. Ceylon Med J 2015;60:126-32.

8. Mittal N, Joshi VK, Srivastava RK, Singh SP. Efficacy of Ayurvedic drugs as compared to chlorhexidine in management of chronic periodontitis: A randomized controlled clinical study. $\mathrm{J}$ Indian Soc Periodontol 2018;22.

9. Safiaghdam H, Oveissi V, Bahramsoltani R, Farzaei MH, Rahimi R. Medicinal plants for gingivitis: a review of clinical trials. Iran J Basic Med Sci 2018;21:978-991

10. Laleman, I, Teughels, W. Novel natural product-based oral topical rinses and toothpastes to prevent periodontal diseases. Periodontol 2020;84: 102-123

11. Al-Kholani Al. Comparison between the efficacy of herbal and conventional dentifrices on established gingivitis. Dent Res J 2011;8:57-63.

12. Cai H, Chen J, Panagodage Perera NK, Liang X. Effects of Herbal Mouthwashes on Plaque and Inflammation Control for Patients with Gingivitis: A Systematic Review and Meta-Analysis of Randomised Controlled Trials. Evid Based Complement Alternat Med 2020;20.

13. Janakiram C, Venkitachalam R, Fontelo P, lafolla TJ, Dye BA. Effectiveness of herbal oral care products in reducing dental plaque \& gingivitis - a systematic review and meta-analysis. BMC Complement Med Ther 2020;20:43.

14. Mehta V, Shetiya SH, Kakodkar P, Janakiram C, Rizwan SA. Efficacy of herbal dentifrice on the prevention of plaque and gingivitis as compared to conventional dentifrice: A systematic review and meta-analysis. J Indian Soc Periodontol 2018;22:379-389.

15. Moher D, Liberati A, Tetzlaff J, Altman DG. Preferred reporting items for systematic reviews and meta-analyses: the PRISMA statement. J. Clin. Epidemiol 2009;62:1006-12.

16. Higgins J, Green S. Cochrane Handbook for Systematic Reviews of Interventions Version 5.1.0 [updated March 2011]. The Cochrane Collaboration, 2011. Available from www.handbook.cochrane.org. [Internet]. Vol. Version 5.1.0.

17. Higgins JPT, Altman DG, Gotzsche PC, Jüni P, Moher D, Oxman AD, et al. The Cochrane Collaboration's tool for assessing risk of bias in randomized trials. BMJ 2011;18;343.

18. Huedo-Medina T, Sanchez-Meca J, Marin-Martinez F, Botella J. Assessing heterogeneity in metaanalysis: Q statistic or I2 index? CHIP doc [internet]. 2006 Jun 1; Available from: https://opencommons.uconn.edu/chip_docs/19

19. Higgins JPT, Thompson SG. Quantifying heterogeneity in a meta-analysis. Stat Med 2002; 21:153958. 
20. Kadam A, Prasad BS, Bagadia D, Hiremath VR. Effect of Ayurvedic herbs on control of plaque and gingivitis: A randomized controlled trial. Ayu 2011;32:532.

21. Patil S, Acharya S, Hathiwala S, Singhal DK, Srinivasan SR, Khatri S. Evaluation of the efficacy of G32 (commercially available ayurvedic preparation) in reducing halitosis-A randomized controlled trial. J. Clin. Diagnostic Res. 2017;11.

22. Saquib S. Anti-Gingivitis Effect of an Ayurvedic Formulation Versus $0.2 \%$ Chlorhexidine on Maintenance Phase: A Randomized Clinical Trial. J Basic Clin Pharm 2017;8.

23. Shetty RN, Shetty SB, Janardhanan S, Shetty S, Shetty S, Raj K. Comparative evaluation of effect of use of toothbrush with paste and munident on levels of Streptococcus mutans and gingival health in children: An in vivo study. J Indian Soc Pedod Prev Dent 2017;35:162.

24. Soman RR, George B, Sebastian ST, Mulamoottil VM, James M. Evaluation of efficacy of an ayurvedic mouthwash on dental plaque and gingivitis: a double blinded parallel randomized controlled study. Braz J Periodontol 2020;30.

25. Vinod KS, Sunil KS, Sethi P, Bandla RC, Singh S, Patel D. A novel herbal formulation versus chlorhexidine mouthwash in efficacy against oral microflora. J Int Soc Prev Community Dent 2018;8:184.

26. Asokan S, Rathan J, Muthu MS, Rathna PV, Emmadi P. Effect of oil pulling on Streptococcus mutans count in plaque and saliva using Dentocult SM Strip mutans test: A randomized, controlled, tripleblind study. J Indian Soc Pedod Prev Dent 2008;26:12.

27. Asokan S, Emmadi P, Chamundeswari R. Effect of oil pulling on plaque induced gingivitis: A randomized, controlled, triple-blind study. Indian J Dent Res 2009;20:47.

28. Botelho MA, Santos RA, Martins JG, Carvalho CO, Paz MC, Azenha C, et al. Comparative effect of an essential oil mouthrinse on plaque, gingivitis and salivary Streptococcus mutans levels: a double blind randomized study. Phytother Res 2009;23:1214-9.

29. Mali GV, Dodamani AS, Karibasappa GN, Vishwakarma P, Jain VM. Comparative evaluation of Arimedadi oil with $0.2 \%$ chlorhexidine gluconate in prevention of plaque and gingivitis: A randomized clinical trial. J. Clin. Diagnostic Res. 2016;10:31.

30. Nagilla J, Kulkarni S, Madupu PR, Doshi D, Bandari SR, Srilatha A. Comparative evaluation of antiplaque efficacy of coconut oil pulling and a placebo, among dental college students: A randomized controlled trial. J. Clin. Diagnostic Res. 2017;11:8.

31. Priyank H, Rishi R, Mahalakshmi V, Purbay S, Kumar C, Verma A. Effect of oil pulling on streptococcus mutans in saliva-a randomised, controlled, triple-blind in vivo study. Int j contemp med res 2017;4:11-5.

32. Aspalli S, Shetty VS, Devarathnamma MV, Nagappa G, Archana D, Parab P. Evaluation of antiplaque and antigingivitis effect of herbal mouthwash in treatment of plaque induced gingivitis: A randomized, clinical trial. J Indian Soc Periodontol 2014;18:48.

33. Bhat N, Mitra R, Oza S, Mantu VK, Bishnoi S, Gohil M, et al. The antiplaque effect of herbal mouthwash in comparison to chlorhexidine in human gingival disease: a randomized placebo 
controlled clinical trial. J. Complement. Integr. Med 2014;11:129-37.

34. Deshmukh MA, Dodamani AS, Karibasappa G, Khairnar MR, Naik RG, Jadhav HC. Comparative evaluation of the efficacy of probiotic, herbal and chlorhexidine mouthwash on gingival health: a randomized clinical trial. Journal of clinical and diagnostic research: J. Clin. Diagnostic Res. 2017;11:13.

35. George J, Hegde S, Rajesh KS, Kumar A. The efficacy of a herbal-based toothpaste in the control of plaque and gingivitis: a clinico-biochemical study. Indian J Dent Res 2009;20:480.

36. Gupta D, Jain A. Effect of cinnamon extract and chlorhexidine gluconate $(0.2 \%)$ on the clinical level of dental plaque and gingival health: A 4-week, triple-blind randomized controlled trial. J Int Acad Periodontol 2015;17:91-8.

37. He J, Deng Y, Zhu F, Zhong T, Luo N, Lei L, et al. The Efficacy and Safety of a Herbal Toothpaste in Reducing Gingivitis: A Double-Blind, Randomized, Placebo-Controlled, Parallel Allocation Clinical Trial. Evid. Based Complementary Altern 2019.

38. Jayashankar S, Panagoda GJ, Amaratunga EA, Perera K, Rajapakse PS. A randomised double-blind placebo-controlled study on the effects of a herbal toothpaste on gingival bleeding, oral hygiene and microbial variables. Ceylon Med J 2011;56.

39. Narayan A, Mendon C. Comparing the effect of different mouthrinses on de novo plaque formation. J Contemp Dent Pract 2012;13:460-3.

40. Siddeshappa ST, Bhatnagar S, Yeltiwar RK, Parvez H, Singh A, Banchhor S. Comparative evaluation of antiplaque and antigingivitis effects of an herbal and chlorine dioxide mouthwashes: $A$ clinicomicrobiological study. Indian J Dent Res 2018;29:34.

41. Baratakke SU, Raju R, Kadanakuppe S, Savanur NR, Gubbihal R, Kousalaya PS. Efficacy of triphala extract and chlorhexidine mouth rinse against plaque accumulation and gingival inflammation among female undergraduates: A randomized controlled trial. Indian J Dent Res 2017;28:49.

42. Bhattacharjee R, Nekkanti S, Kumar NG, Kapuria K, Acharya S, Pentapati KC. Efficacy of triphala mouth rinse (aqueous extracts) on dental plaque and gingivitis in children. J Investig Clin Dent 2015;6:206-10.

43. Chainani SH, Siddana S, Reddy CV, Manjunathappa TH, Manjunath M, Rudraswamy S. Antiplaque and antigingivitis efficacy of triphala and chlorhexidine mouthrinse among schoolchildren-a crossover, double-blind, randomised controlled trial. Oral Health Prev Dent 2014;12:209-17.

44. Gupta D, Gupta RK, Bhaskar DJ, Gupta V. Comparative evaluation of terminalia chebula extract mouthwash and chlorhexidine mouthwash on plaque and gingival inflammation-4-week randomised control trial. Oral Health Prev Dent 2015;13:5-12.

45. Mamgain P, Kandwal A, Mamgain RK. Comparative evaluation of triphala and ela decoction with $0.2 \%$ chlorhexidine as mouthwash in the treatment of plaque-induced gingivitis and halitosis: a randomized controlled clinical trial. J Evid Based Complementary Altern Med 2017;22:468-72.

46. Naiktari RS, Gaonkar P, Gurav AN, Khiste SV. A randomized clinical trial to evaluate and compare the efficacy of triphala mouthwash with $0.2 \%$ chlorhexidine in hospitalized patients with periodontal 
diseases. J Periodontal Implant Sci 2014;44:134-40.

47. Nayak SS, Ankola AV, Metgud SC, Bolmal U. Effectiveness of mouthrinse formulated from ethanol extract of Terminalia chebula fruit on salivary Streptococcus mutans among 12 to 15 year old school children of Belgaum city: A randomized field trial. J Indian Soc Pedod Prev Dent 2012;30:231.

48. Kumar GR, Devanand G, John BD, Ankit Y, Khursheed O, Sumit M. Preliminary antiplaque efficacy of aloe vera mouthwash on 4 day plaque re-growth model: randomized control trial. Ethiop J Health Sci 2014;24:139-44.

49. Khatri SG, Samuel SR, Acharya S, Patil ST. Antiplaque, Antifungal Effectiveness of Aloevera Among Intellectually Disabled Adolescents: Pilot Study. Pediatr. Dent. 2017;39:434-8.

50. Oliveira SM, Torres TC, Pereira SL, Mota OM, Carlos MX. Effect of a dentifrice containing Aloe vera on plaque and gingivitis control: A double-blind clinical study in humans. J. Appl. Oral Sci. 2008;16:293-6.

51. Balappanavar AY, Sardana V, Singh M. Comparison of the effectiveness of $0.5 \%$ tea, $2 \%$ neem and $0.2 \%$ chlorhexidine mouthwashes on oral health: A randomized control trial. Indian J Dent Res 2013;24:26.

52. Jalaluddin M, Rajasekaran UB, Paul S, Dhanya RS, Sudeep CB, Adarsh VJ. Comparative Evaluation of Neem Mouthwash on Plaque and Gingivitis: A Double-blind Crossover Study. J. Contemp. Dent. Pract 2017;18:567-71.

53. Pai MR, Acharya LD, Udupa N. Evaluation of antiplaque activity of Azadirachta indica leaf extract gel -a 6-week clinical study. J. Ethnopharmacol. 2004;90:99-103.

54. Kandwal A, Mamgain RK, Mamgain P. Comparative evaluation of turmeric gel with $2 \%$ chlorhexidine gluconate gel for treatment of plaque induced gingivitis: A randomized controlled clinical trial. Ayu 2015;36:145.

55. Singh V, Pathak AK, Pal M, Sareen S, Goel K. Comparative evaluation of topical application of turmeric gel and $0.2 \%$ chlorhexidine gluconate gel in prevention of gingivitis. Natl. j. maxillofac. surg. 2015;6:67.

56. Waghmare PF, Chaudhari AU, Karhadkar VM, Jamkhande AS. Comparative evaluation of turmeric and chlorhexidine gluconate mouthwash in prevention of plaque formation and gingivitis: A clinical and microbiological study. J Contemp Dent Pract 2011;12:221-4.

57. Abdulbaqi HR, Himratul-Aznita WH, Baharuddin NA. Evaluation of Salvadora persica L. and green tea anti-plaque effect: a randomized controlled crossover clinical trial. BMC Complement Altern Med 2016;16:1-7.

58. Sarin S, Marya C, Nagpal R, Oberoi SS, Rekhi A. Preliminary clinical evidence of the antiplaque, antigingivitis efficacy of a mouthwash containing $2 \%$ green tea-a randomised clinical trial. Oral Health Prev Dent 2015;13:197-203.

59. da Silva Pereira SL, de Oliveira JW, Ângelo KK, da Costa AM, Costa FN. Clinical effect of a mouth rinse containing Ocimum gratissimum on plaque and gingivitis control. J Contemp Dent Pract 2011;12:350-5. 
60. Gupta D, Bhaskar DJ, Gupta RK, Karim B, Jain A, Singh R, et al. A randomized controlled clinical trial of Ocimum sanctum and chlorhexidine mouthwash on dental plaque and gingival inflammation. $J$ Ayurveda Integr Med 2014;5:109

\section{Table 1}

Table 1 is available in the supplementary files section.

\section{Figures}

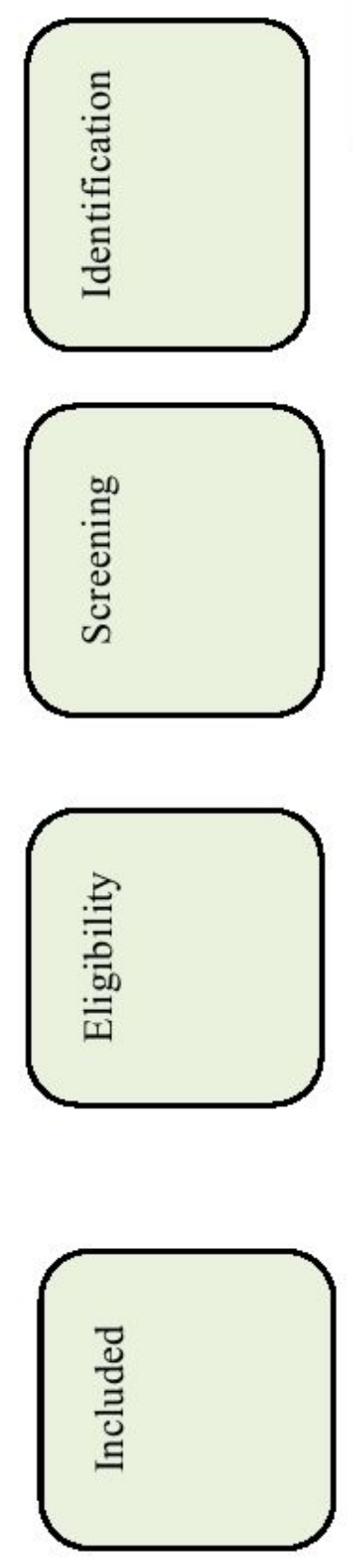

Records identified through databases searching $(\mathrm{n}=509)$
Additional records identified through other sources

$$
(n=45)
$$

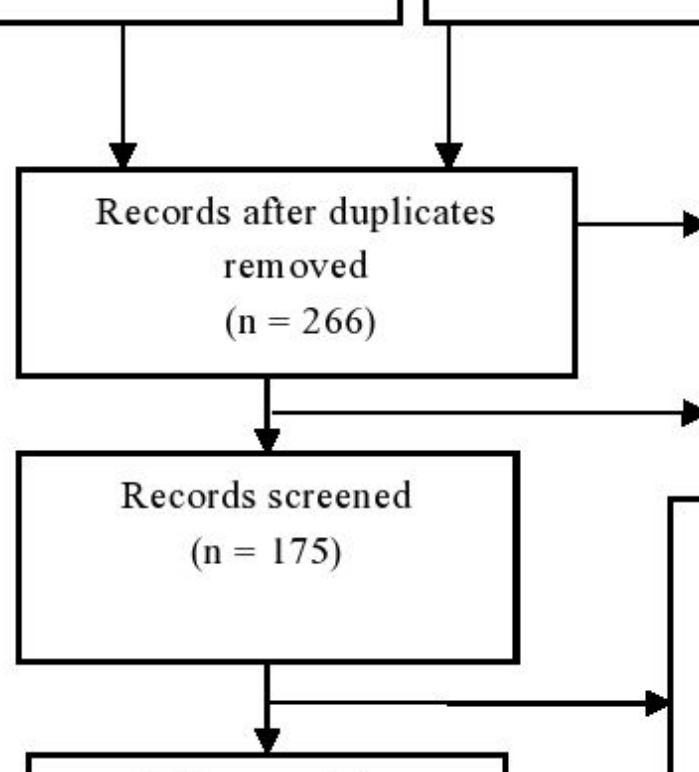

Duplicates excluded $(\mathrm{n}=288)$

Records excluded

$$
(\mathrm{n}=91)
$$

Excluded

After viewing title and abstract $(n=49)$

Full text not accessible $(n=26)$

Non-English articles $(\mathrm{n}=16)$

Full-text articles excluded with reasons:

Variation in RCT design $(\mathrm{n}=11)$

Follow-up variation $(\mathrm{n}=09)$

Missing values $(\mathrm{n}=08)$

Without relevant indices $(\mathrm{n}=08)$

Other outcomes $(n=07)$

Studies included in the meta-analysis

$$
(n=41)
$$


Figure 1

Study flow diagram

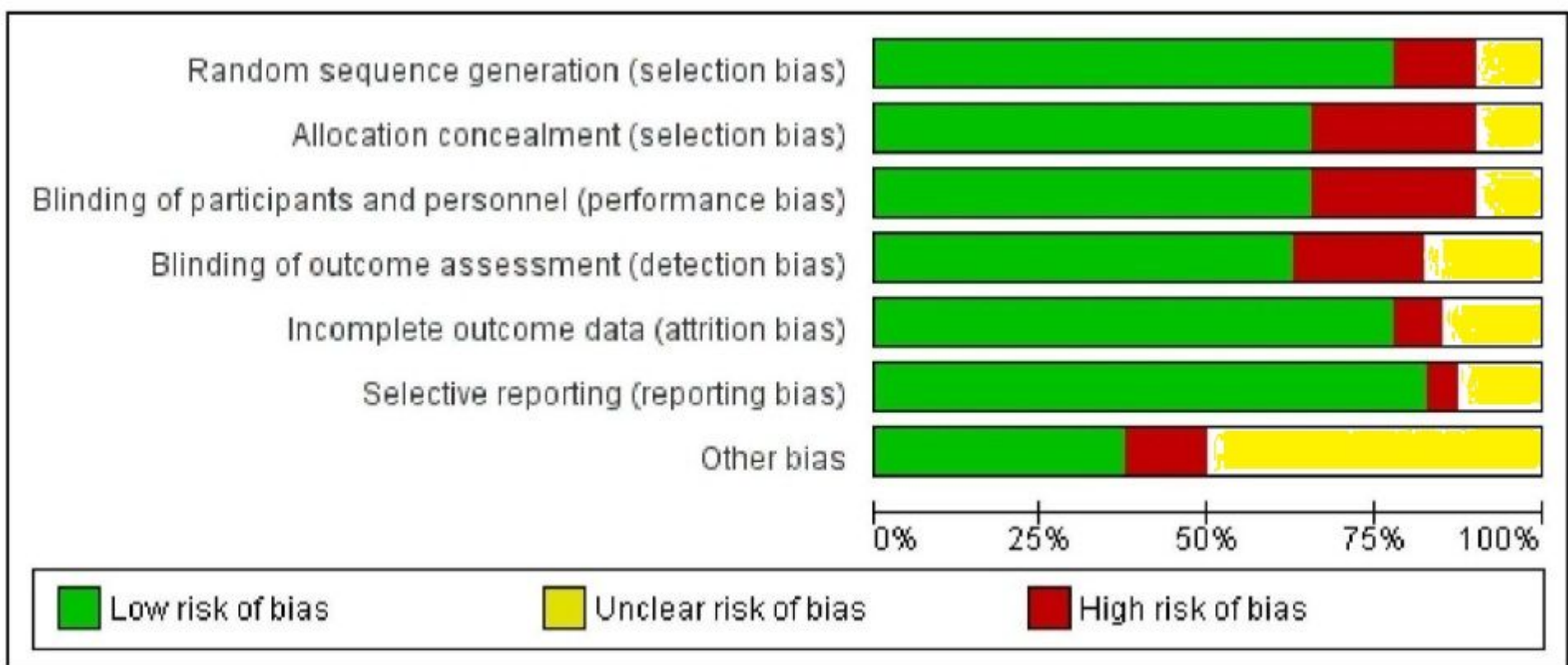

Figure 2

Risk of Bias graph: review authors' judgments about each risk of bias item presented as percentages across all included studies. 

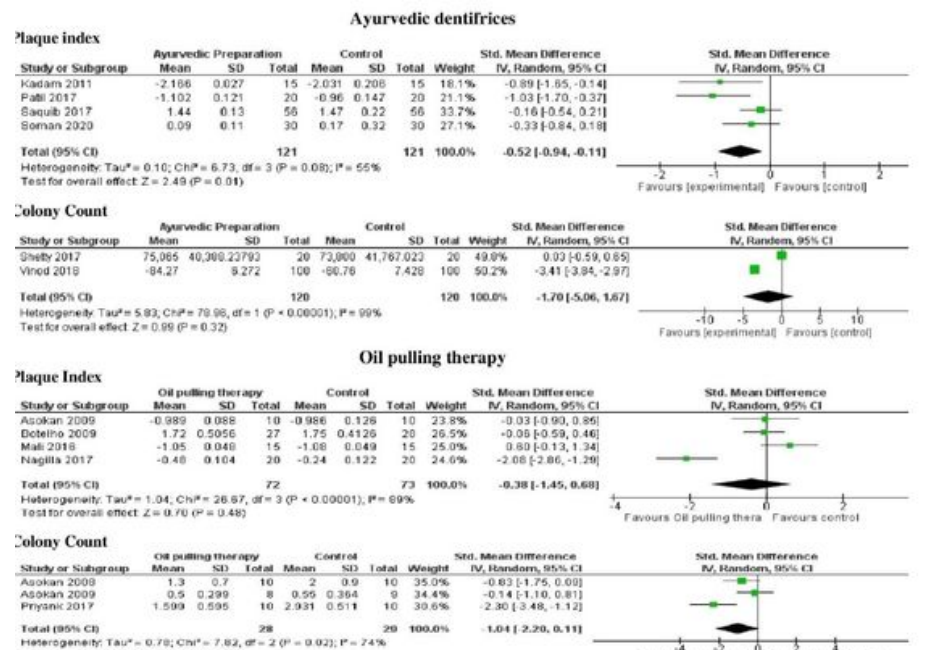

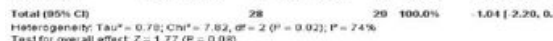

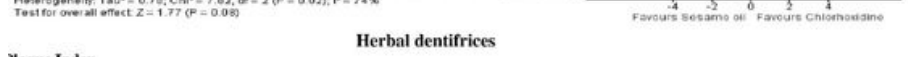

laque Index

Herbal dentifrices
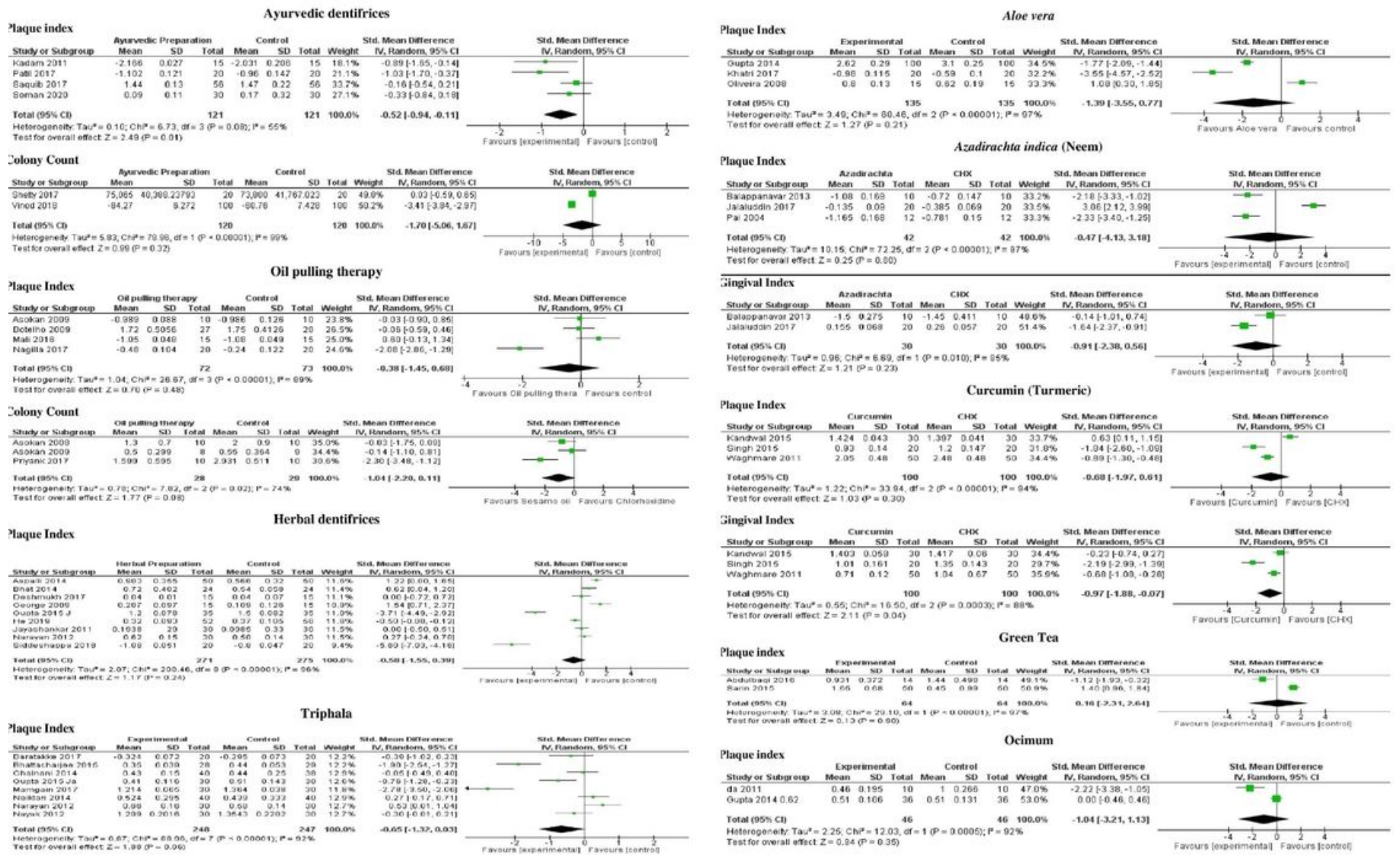

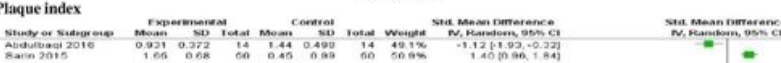

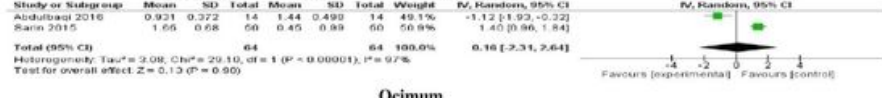

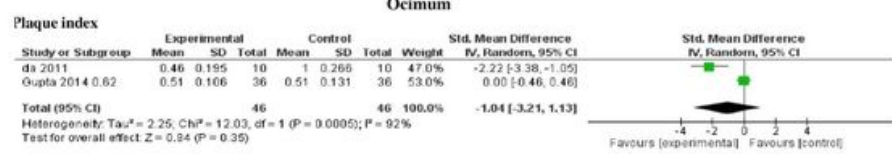

${ }^{*} P$-value $<0.05$ is considered significant.

" $P$-value $<0.05$ is considered significant.

A

\section{Figure 3}

Figure 3a: Forest plots of included studies

Figure $3 b$ : Forest plots of included studies 

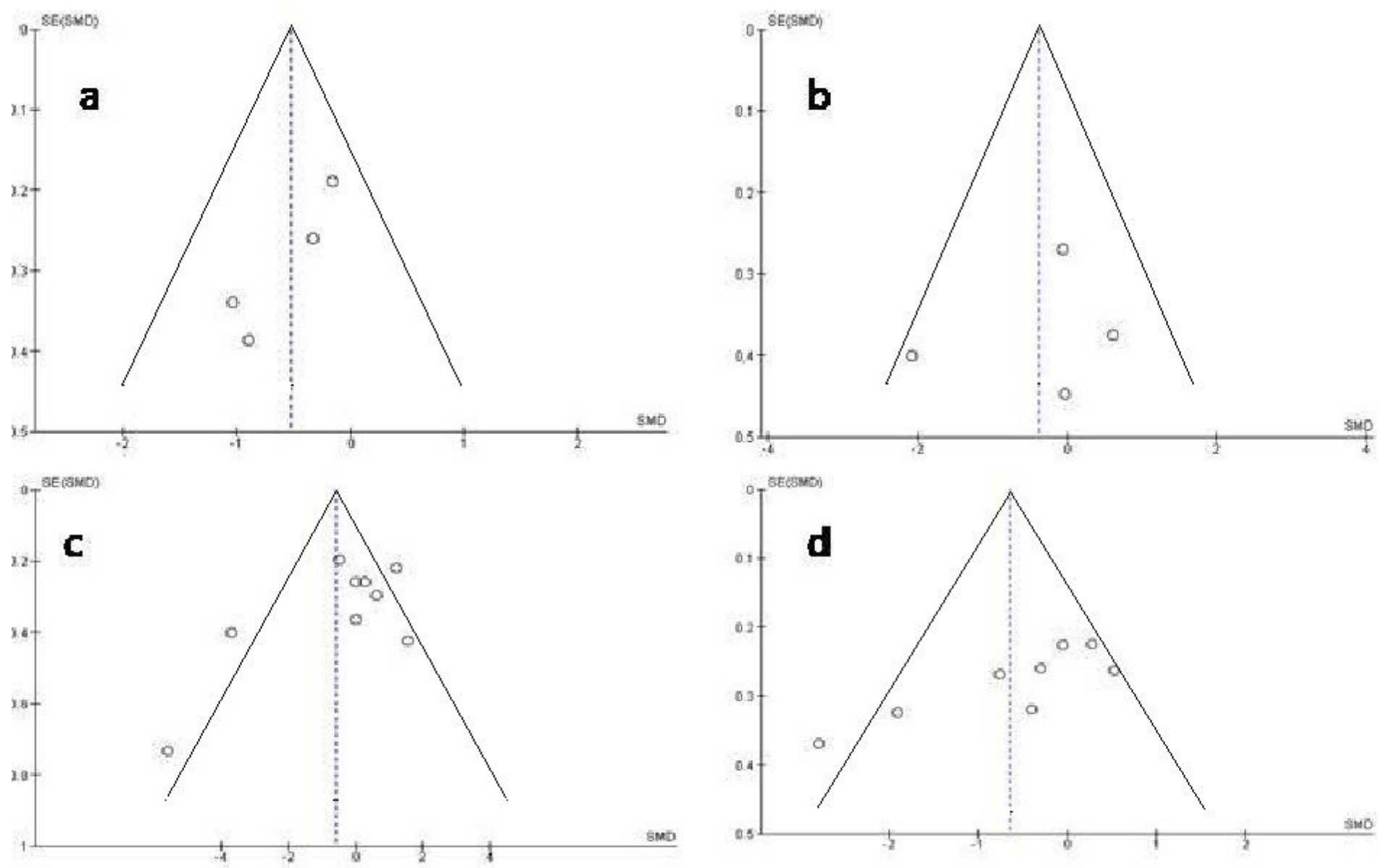

Figure 4

Funnel plot of comparison: a. Ayurvedic preparation, b. Oil pulling therapy, c. Herbal Preparations and d. Triphala vs. Control, Outcome: Plaque Index.

\section{Supplementary Files}

This is a list of supplementary files associated with this preprint. Click to download.

- Table1.docx 